\title{
Low power design of ultra wideband PLL using 90 nm CMOS technology
}

Fadhilah Binti Noor Al Amin, Nabihah Ahmad, Siti Hawa Ruslan

Faculty of Electrical and Electronic Engineering, Universiti Tun Hussein Onn Malaysia, Malaysia

\begin{tabular}{l} 
Article Info \\
\hline Article history: \\
Received Mar 1, 2020 \\
Revised Apr 19, 2020 \\
Accepted May 4, 2020 \\
\hline
\end{tabular}

\section{Keywords:}

Charge pump

Low pass filter

Phase frequency detector

Phase locked loop

Voltage controlled oscillator

\begin{abstract}
The rapid growth of the electronic system has become one of the challenges in the high performance of Very Large Scale Integration (VLSI) design and has contributed to the evolution of Phase Locked Loop (PLL) system design as one of the inevitable and significant necessities in the modern days. This design focus on the development of PLL system that can operate at a high performance within the Ultra-Wideband (UWB) frequency but consume low power that may be useful for future device implementation in the communication system. All proposed sub modules of PLL is highly suitable for low power and high speed application as each of them consumes overall power consumption around $2 \mu \mathrm{W}$ until $1 \mathrm{~mW}$ with frequency from $3.1 \mathrm{GHz}$ to $10.6 \mathrm{GHz}$. All the design architecture, schematic, simulation and analysis are implemented using Synopsys Tool in $90 \mathrm{~nm}$ CMOS technology. Through the overall analysis, it can be concluded that this proposed sub modules design of the PLL system has better performance compared to previous work in terms of power consumption and frequency.
\end{abstract}

Copyright (c) 2020 Institute of Advanced Engineering and Science. All rights reserved.

\section{Corresponding Author:}

Fadhilah Binti Noor Al Amin,

Faculty of Electrical and Electronic Engineering (FKEE),

Universiti Tun Hussein Onn Malaysia (UTHM),

86400 Parit Raja, Batu Pahat, Johor, Malaysia.

Email: fadhilahamin90@gmail.com

\section{INTRODUCTION}

A PLL system is a closed loop feedback control system that is capable of generating a clock signal that has a fixed relationship to the reference clock signal. The main concept of this system is to match the reference and the feedback signals in phase which is the lock condition by comparing both signals [1]. Figure 1 shows the block diagram of PLL that consists of three sub module blocks namely Phase Frequency Detector (PFD), Charge Pump (CP) and Loop Filter (LF) and Voltage Controlled Oscillator (VCO).

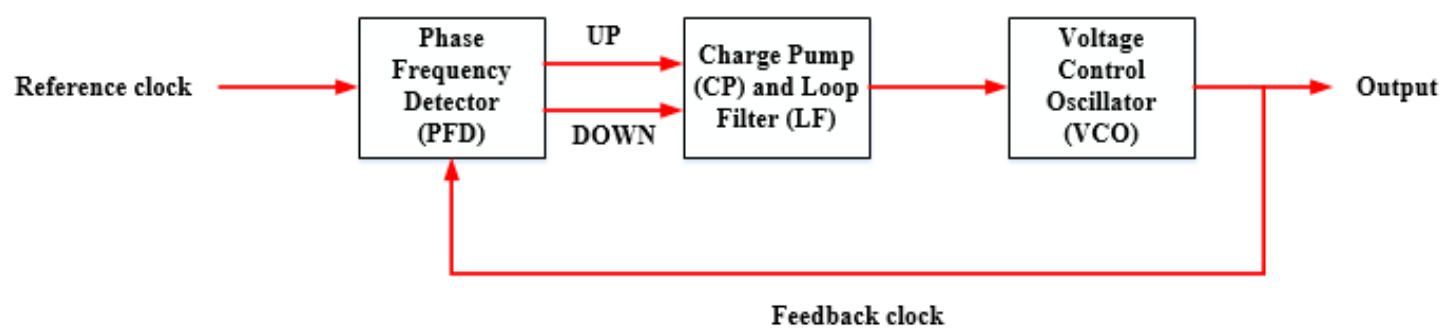

Figure 1. Basic block diagram of PLL system [2] 
Designing a high performance that can operate data at very fast speed within a short time and low power dissipation is demanding nowadays especially for the portable and wireless devices that used battery powered. It is because people adored to have a device that capable to be handled and carried away easily from one to another place. Thus, the devices that can operate faster and having a long-lifetime was a total demand. So it is a challenge to design PLL system that focus in minimize power consumption while maintaining high frequency of UWB.

Some studies have been done regarding on the PLL system using various sub module blocks where in [3-6] shown some improvement in terms of frequency but however, it could not achieve the low power issue efficiently. To overcome the low power issue, a PLL system with various sub module of high speed phase frequency detector, conventional charge pump with second order low pass filter and single ended differential pair of voltage controlled ring oscillator with three stages delay cell has been chosen as the optimization method to improve the PLL system. The overall power consumption of the PLL system can be reduced mainly by minimizing the power consumption in charge pump and VCO circuit where both circuits can contribute about $20 \%$ to $50 \%$ of total power consumption of the PLL. By reducing this power consumption, the contribution of the charge pump and VCO could lead to a reduction of the overall power consumed by the PLL system. This paper is organized as follows: in Section 2, the description of the PLL circuit with various sub modules and illustrations of related mathematical modeling are described. Then, the overall result of the PLL system used in this study is discussed in Section 3. Lastly, summary and conclusion are presented in Section 4.

\section{RESEARCH METHOD}

\subsection{Phase frequency detector}

Phase frequency detector is one of the important blocks in the PLL system. Figure 2 shows the block diagram of PFD where it is used to compare the phase and frequency difference of the two clock input signals which are clock reference and clock from VCO where the reference clock $\left(\mathrm{CLK}_{\mathrm{ref}}\right)$ acts as first clock input and the feedback signal that coming from VCO $\left(\mathrm{CLK}_{\mathrm{vco}}\right)$ as the second clock input. By depending on the phase and frequency difference of the two clock input signals, it will provides two output signals that are UP and DOWN are generated. The output of PFD is then fed to the charge pump to generate the related control signal for VCO.

A proposed design of PFD circuit known as High Speed Phase Frequency Detector (HSPFD) is present in Figure 3. Compared to traditional PFD [7] that used two D Flip-flop, two inverters and an AND gate at the feedback path, the proposed HSPFD circuit consists of two D Flip-flop, two inverters and two NAND gates that acts to reduce power consumption and reach high speed by detect both rising and falling edges of the input signals.

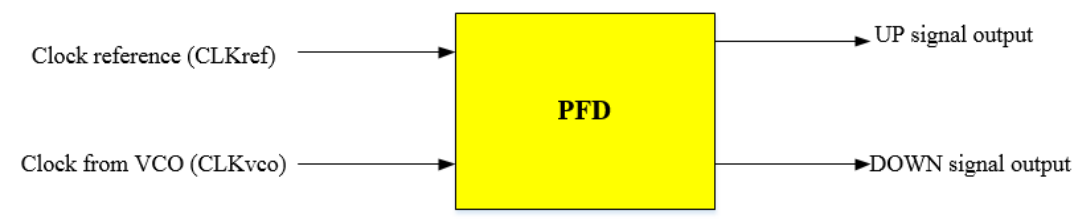

Figure 2. Block diagram of PFD [8]

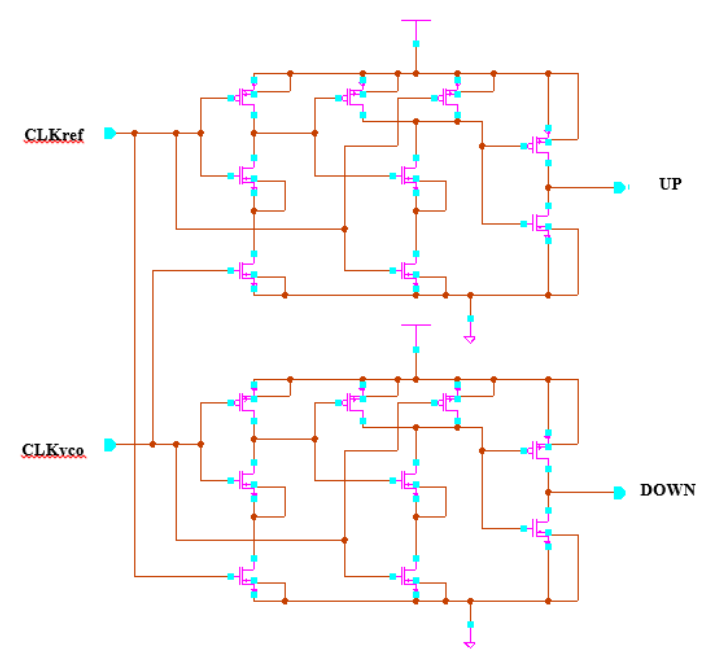

Figure 3. High speed phase frequency detector (HSPFD) circuit 


\subsection{Charge pump}

Charge pump is an essential building block in PLL where it is controlled by three states of PFD. The main function of the charge pump is to convert the phase or frequency difference information from the PFD into an analog signal that will be fed to the input loop filter [9]. The charge pump injects, subtracts, or stored charge across a capacitor in the low pass filter by depending on the output of a sequential of PFD circuit. Figure 4 shows the basic architecture of charge pump where it consists of current source and switches. The output signal of the charge pump is then connected to low pass filter that will integrates the charge pump output current to an equivalent VCO control voltage (Vctrl). When S1 is closed, current flow into the low pass filter and increasing the control voltage to VCO. While when S2 is closed, current flow out of the low pass filter and decreasing the control voltage to the VCO [10]. Figure 5 shows the Conventional charge pump circuit that consists of 15 transistors where this circuit is used to combine two output form PFD that are UP and DOWN into a single output that will be pumped into a loop filter.

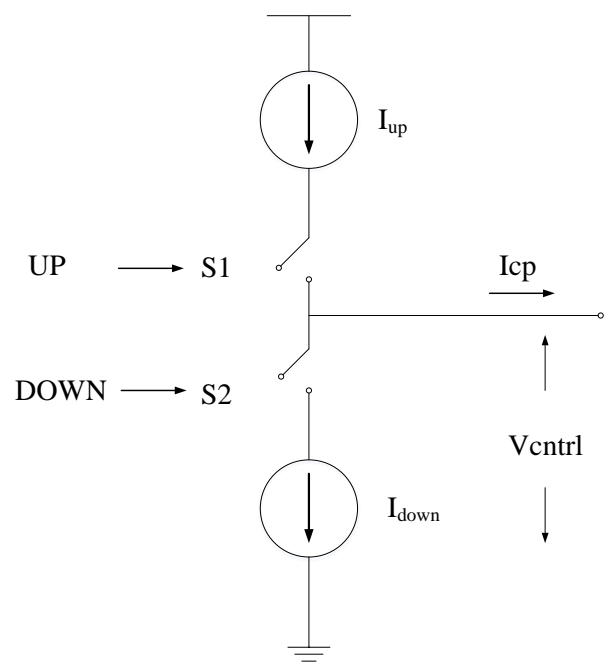

Figure 4. Basic architecture of charge pump [10]

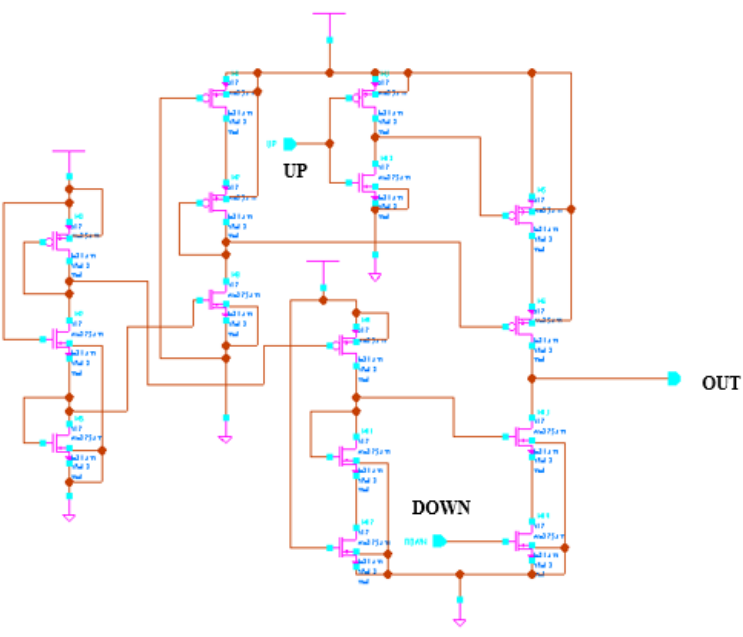

Figure 5. Conventional charge pump circuit

\subsection{Loop filter}

For the loop filter, it needs to be chosen carefully to avoid irrelevant values because the actual circuit of loop filter is generally remarkably simple but it has a major impact on the performance of the loop. Loop filter is functioning as a converter to convert the current coming from the charge pump to control voltage that is directly connected to VCO to control the frequency of VCO [11]. Figure 6 shows second order passive filter circuit that used in this paper where it consists of a resistor and a capacitor in series and other capacitor is used to reduce spikes which is parallel to both of them.

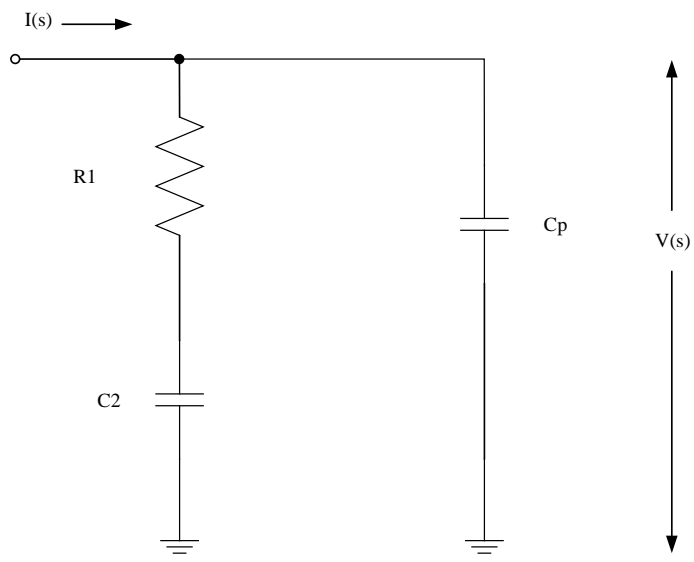

Figure 6. Second order passive filter [11] 
By refering to the method introduced by Ken Holladay [11], the value of capacitance and resistance are calculated from the following equations.

$$
\begin{aligned}
& F_{\text {step }}=F_{\text {osc max }}-F_{\text {osc min }} \\
& N=\frac{F_{\text {osc max }}}{F_{\text {step }}} \\
& F_{N}=\frac{2 \times B P_{P L L}}{2 \pi \times\left(\xi+\frac{1}{4 \times \xi}\right)} \\
& C_{2}=\frac{I_{C P} \times K_{V C O}}{N \times\left(2 \pi \times F_{N}\right)^{2}} \\
& R_{1}=2 \times \xi \times \sqrt{\frac{N}{I_{C P} \times K_{V C O} \times C_{2}}} \\
& C_{1}=\frac{C_{2}}{10}
\end{aligned}
$$

where $F_{\text {step }}$ represents the frequency step while $F_{\text {osc max }}$ and $F_{\text {osc min }}$ represents the maximum oscillator frequency and the minimum oscillator frequency from the frequency range while $N$ represents the multiplication factor. In (3), $F_{N}$ represents the natural frequency while $B P_{P L L}$ represents the loop bandwidth and $\xi$ represents the damping factor. In (4), $I_{C P}$ and $K_{V C O}$ represents the charge pump current and VCO sensitivity. Meanwhile, from (4), (5) and (6), the value of capacitor $C_{1}$ is defined by calculating the value of $C_{2}$ and $R_{1}$. Table 1 shows the summary of parameter for second order low pass filter.

Table 1. Parameter of second order passive filter

\begin{tabular}{cc}
\hline Parameter & Values \\
\hline Frequency range, $F_{\text {osc }}$ & $3.1 \mathrm{GH}-10.6 \mathrm{GHz}$ \\
VCO sensitivity, $K_{\text {sco }}$ & $10 \mathrm{KHz}$ \\
Charge pump current, $I_{c p}$ & $5 \mu \mathrm{A}$ \\
loop bandwidth, $B P_{P L L}$ & $100 \mathrm{KHz}$ \\
Damping factor, $\xi$ & 0.707 \\
Frequency step, $F_{\text {step }}$ & $7.5 \mathrm{GHz}$ \\
Natural frequency, $F_{n}$ & $30.013 \mathrm{KHz}$ \\
Multiplication factor, N & 1.4133 \\
$\mathrm{R}_{1}$ & $7.53662 \mathrm{M} \Omega$ \\
$\mathrm{C}_{1}$ & $99.493 \mathrm{fF}$ \\
$\mathrm{C}_{2}$ & $0.99493 \mathrm{pF}$ \\
\hline
\end{tabular}

\subsection{Voltage controlled oscillator}

Voltage controlled oscillator or known as VCO is a crucial block because the VCO performance governs many aspects of the performance of the whole PLL system. It is also able to produce an oscillating frequency from an input voltage. In VCO, the number of stages can affect the output frequency of VCO. By changing the number of stages, the oscillation frequency of VCO could be boosted. The increasing of number of staged may improve the phase noise as the phase noise was being filtered at each stage [12]. But, the VCO design with higher number of stages will increase the complexity of circuit and at the same time rise the power consumption [13]. Figure 7 shows the block diagram of voltage controlled ring oscillator (VCRO) that using single-ended differential pair configuration ring oscillator with three delay stages [14] and Figure 8 shows the proposed VCRO schematic circuit design with three delay stages that consist of an inverter and three delay stages.

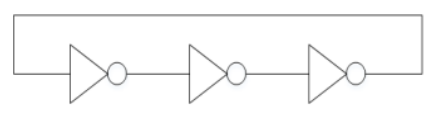

Figure 7 Block diagram of VCRO [14] 


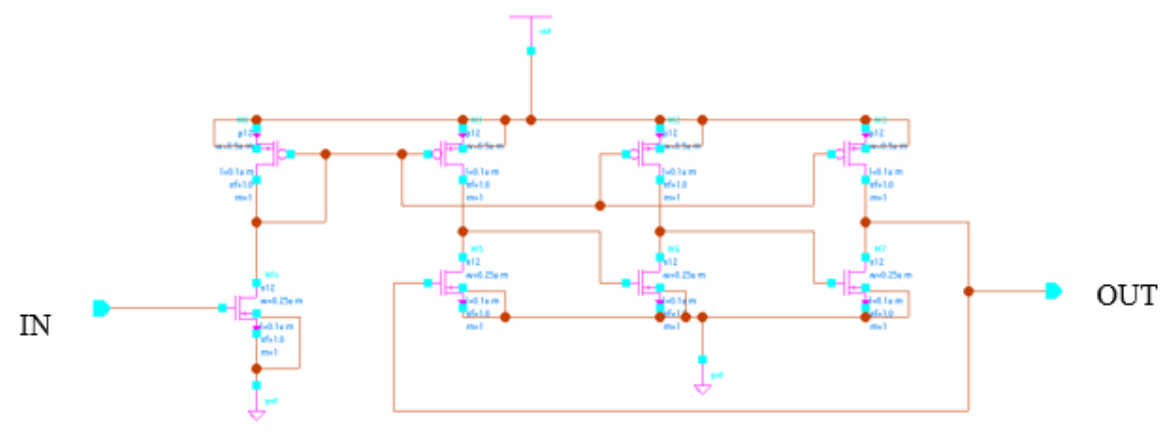

Figure 8 Schematic circuit of VCRO

\section{RESULTS AND ANALYSIS}

The schematic circuit of all sub module designs have been designed using Schematic Editor of 90 $\mathrm{nm}$ CMOS technology of Synopsys Tool. The setting of the simulation was done by using Simulation and Analysis Environment (SAE) while the output waveform was evaluated and analyzed by using WaveViewTool. The discussion of each sub module explained in sub section below.

\subsection{High speed phase frequency detector (HSPFD)}

The proposed design of PFD was operated at $1.2 \mathrm{~V}$ power supply, $1 \mathrm{GHz}$ input frequency and load capacitance of $0.01 \mathrm{pF}$. There is three different output condition that occurs in the PFD that are lock condition, CLK $\mathrm{K}_{\mathrm{ref}}$ leading and $\mathrm{CLK}_{\mathrm{vco}}$ leading. In Figure 9, both UP and DOWN are in lock condition where both input $\mathrm{CLK}_{\mathrm{ref}}$ and $\mathrm{CLK}_{\mathrm{vco}}$ are set in the same delay time that is $0.5 \mathrm{~ns}$. Figure 10 shows the simulation waveform when the $\mathrm{CLK}_{\text {ref }}$ is in leading condition where $\mathrm{CLK}_{\text {ref }}$ is leading with $0.5 \mathrm{~ns}$ delay time and followed by $\mathrm{CLK}_{\mathrm{vco}}$ in $100 \mathrm{ps}$. When the $\mathrm{CLK}_{\mathrm{ref}}$ leading, it will charge upper D Flip-flop and cause output signal UP high. While Figure 11 shows the $\mathrm{CLK}_{\mathrm{vco}}$ leading condition where this condition is vice versa from the $\mathrm{CLK}_{\mathrm{ref}}$ leading condition. When $\mathrm{CLK}_{\mathrm{vco}}$ is leading with $0.5 \mathrm{~ns}$ delay time and followed by $\mathrm{CLK}_{\mathrm{vco}}$ in $100 \mathrm{ps}$, it will charge lower D Flip-flop and resulting output DOWN high. Table 2 shows the comparison of power consumption and frequency between the proposed design and previous studies design.

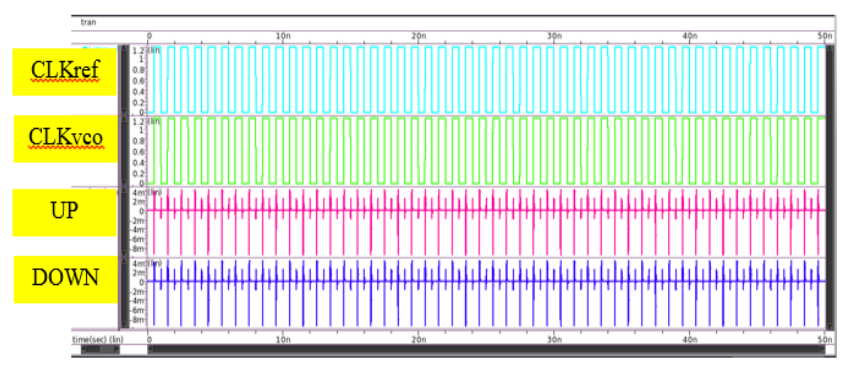

Figure 9. Output waveform in lock condition

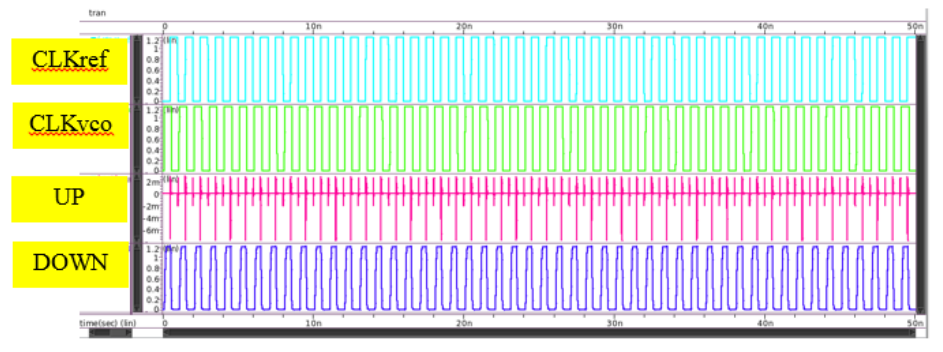

Figure 10. Output waveform in $\mathrm{CLK}_{\text {ref }}$ leading condition 


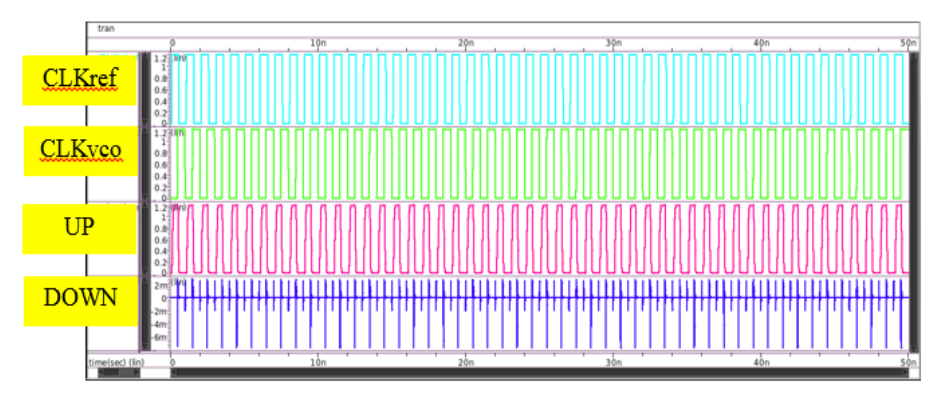

Figure 11. Output waveform in CLK $_{\mathrm{VCO}}$ leading condition

Table 2. Comparison of the proposed PFD design with previous studies

\begin{tabular}{ccc}
\hline No & Power $(\mu \mathrm{W})$ & Frequency $(\mathrm{GHz})$ \\
\hline Proposed Design & 1.512 & 3.3 \\
{$[15]$} & 0.116 & 1 \\
{$[16]$} & 8.513 & 1 \\
{$[17]$} & 79 & 0.1 \\
{$[18]$} & 6.951 & 1 \\
{$[19]$} & 10 & 1.5 \\
\hline
\end{tabular}

\subsection{Conventional charge pump with second order passive filter}

Figure 12 and Figure 13 shows the output waveform in charging or discharging condition. When the input UP is high and input DOWN is low, the output of the charge pump is in charging condition. While the discharging condition occurs when the input UP is low and input DOWN is high. In this proposed design, the power supply is set to $1.2 \mathrm{~V}$ and load capacitance of $0.01 \mathrm{pF}$ is used for simulation analysis. While for Table 3 shows the comparison of power consumption and frequency between the proposed design and previous techniques used in charge pump and loop filter.

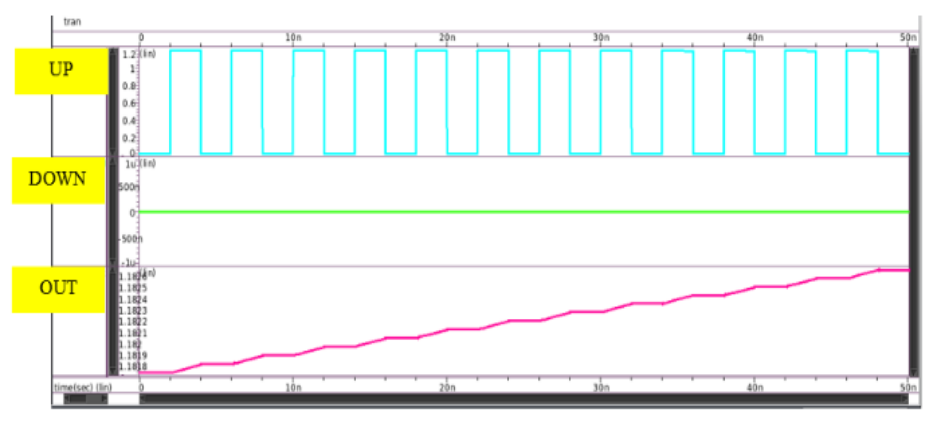

Figure 12. Output waveform in charging condition

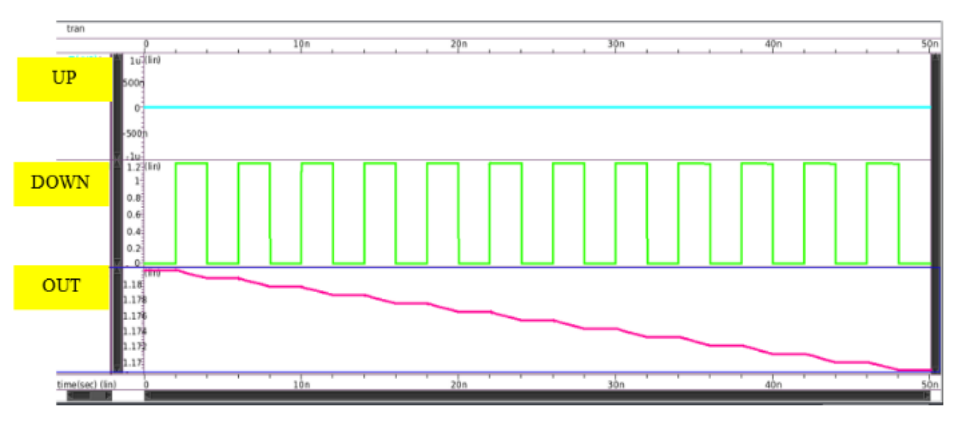

Figure 13. Output waveform in discharging condition 
Table 3. Comparison between the proposed charge pump and loop filter with previous studies

\begin{tabular}{ccc}
\hline No & Power $(\mu \mathrm{W})$ & Frequency $(\mathrm{GHz})$ \\
\hline Proposed Design & 1.235 & 3.2 \\
{$[20]$} & 2.07 & 4.7 \\
{$[21]$} & 5 & 1.53 \\
{$[22]$} & 37 & 0.5 \\
{$[23]$} & 6.76 & 2.2 \\
{$[24]$} & 6.69 & - \\
\hline
\end{tabular}

\subsection{Single ended differential pair of voltage controlled ring oscillator (VCRO)}

Figure 14 shows the output waveform of single ended differential pair of VCRO with three stages delay cell where voltage supply of $1.2 \mathrm{~V}$, voltage control of $2 \mathrm{~V}$ along with $6 \mathrm{GHz}$ of initial sinusoidal frequency, $1 \mathrm{~V}$ amplitude and $2 \mathrm{pF}$ of load capacitance were supplied to the input of VCRO. The simulation setting of transient analysis starts at $0.5 \mathrm{~ns}$ and stops at $3 \mathrm{~ns}$ and gives result of smaller voltage and same shape to the output of VCRO because the used of three stages of delay cell where it invert the input pulse of VCRO three times and gives the output waveform as Figure 14. While Table 4 shows the comparison of VCRO in different technology.

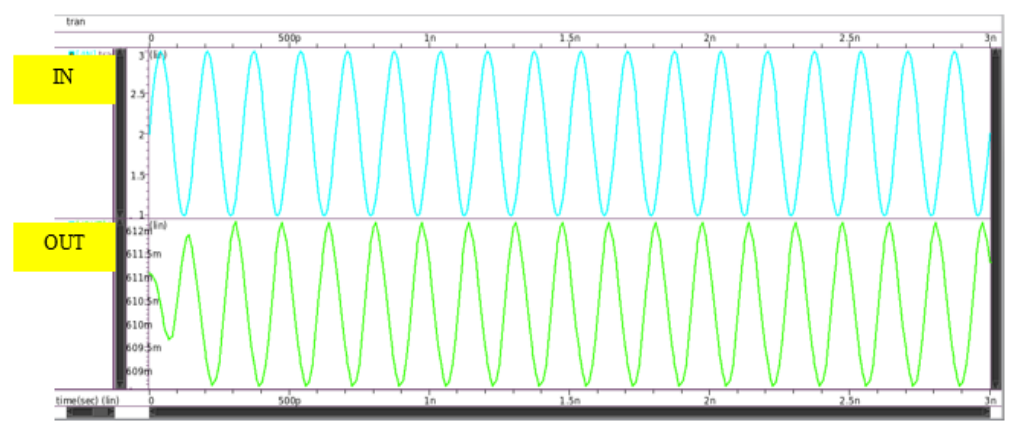

Figure 14. Output waveform in discharging condition

Table 4. Comparison of VCRO in different technology

\begin{tabular}{ccc}
\hline No & Power $(\mu \mathrm{W})$ & Frequency $(\mathrm{GHz})$ \\
\hline Proposed Design & 687 & $6.5-7.138$ \\
{$[25]$} & 1050 & $0.9-1.25$ \\
{$[26]$} & 835 & $3.328-4.606$ \\
{$[27]$} & 750 & $3.500-4.500$ \\
{$[28]$} & 50 & $3.500-4.500$ \\
\hline
\end{tabular}

\section{CONCLUSION}

This paper has presented a PLL design with different sub modules that has been designed and implemented using Synopsys Tools in $90 \mathrm{~nm}$ CMOS technology. The proposed design reveals the behavior of each sub modules in the PLL system that obtain power consumption around $2 \mu \mathrm{W}$ until $1 \mathrm{~mW}$ and UWB frequency from $3.1 \mathrm{GHz}$ to $10.6 \mathrm{GHz}$ that has great potential to be implantable in wireless and communication system. The power consumption achieved for HSPFD is $1.152 \mu \mathrm{W}$, while power consumption for Conventional Charge Pump with Second Order Passive Filter and VCRO are 1.235 $\mu \mathrm{W}$ and $687 \mu \mathrm{W}$. At the same time, the proposed design of HSPFD and for Conventional Charge Pump with Second Order Passive Filter achieved frequencies of $3.3 \mathrm{GHz}$ and $3.2 \mathrm{GHz}$. While for VCRO, it is able to operate in the range of 6.5 to $7.138 \mathrm{GHz}$.

\section{ACKNOWLEDGEMENTS}

The authors would like to express gratitude for financial support and contributions from Ministry of Education (MOE) Malaysia under Fundamental Research Grant Scheme (FRGS) vot number 1630. 


\section{REFERENCES}

[1] S. M. Jung, and J. M. Roveda, "Design of low jitter phase-locked loop with closed loop voltage controlled oscillator." Wireless and Microwave Technology Conference (WAMICON), 2015 IEEE $16^{\text {th }}$ Annual, pp. 1-4, 2015.

[2] S. Maji, and S. M. S. K. Saw. "Phase Locked Loop-A Review," International Journal of Engineering Research \& Technology (IJERT), CMRAES-Conference Proceedings, vol. 4, no. 2, 2016.

[3] S. V. R. Kaipu, K. Vaish, S. Komatireddy, A. Sood, and M. Goswami, "Design of a low power wide range phase locked loop using 180nm CMOS technology," Signal Processing and Communication (ICSC), 2016 International Conference, pp. 443-447, 2016.

[4] B. Yuan, and H. Liu, "A generalized low power and lower jitter charge pump PLL," Microwave and Millimeter Wave Circuits and System Technology (MMWCST), 2013 International Workshop, pp. 471-474, 2013.

[5] S. W. Chu, and C. K. Wang, "An $80 \mathrm{GHz}$ wide tuning range Push-push VCO with boosted full-wave rectification technique in 90 nm CMOS," IEEE Microwave and Wireless Components Letters, vol. 22, no. 4, pp. 203-205, 2012.

[6] K. P. Thakore, H. P. Parmar, and N. M. Devashrayee, "Low power and low jitter phase frequency detector for phase lock loop," International Journal of Engineering Science and Technology, vol. 3, no. 3, pp. 1998-2004, 2011.

[7] Tonk, Anu. "A comparative review and analysis of different phase frequency detectors for phase locked loops," International Journal of Engineering Research and General Science vol. 3, no. 6, pp. 618-632, 2015.

[8] K. P. Thakore, H. P. Parmar, and N. M. Devashrayee, "High speed PFD with charge pump and loop filter for low jitter and low power PLL" International Journal of Electronic and Computer Technology (IJECT), vol. 2, no. 2, pp. 55-59, pp. 397-405, 2011.

[9] Metange PN, Khanchandani KB. "Analysis and design of high performance phase frequency detector, charge pump and loop filter circuits for phase locked loop wireless applications," Indonesian Journal of Electrical Engineering and Computer Science, vol. 4, no. 2, pp. 397-405, 2016.

[10] A. Agrawal, R. Khatri, "Design of low power, high gain PLL using CS-VCO on 180nm Technology," International Journal of Computer Application, vol. 122, no.18, pp. 26-30, 2015.

[11] K. Holladay and F. Microelectronics, "Design a PLL for a specific loop bandwidth," EDN Network, vol. 45, no. 21, pp. $173-175,2000$.

[12] B. Goyal, S. Suman, and P. K. Ghosh, "Design and analysis of improved performance ring VCO based on differential pair configuration," 2016 International Conference on Electrical, Electronics, and Optimization Techniques (ICEEOT), pp. 3468-3472, 2016.

[13] R. Nandini, and S. R. Himadri, "Comparison of low power phase frequency detectors for delay locked loop," International Journal of Engineering Research and Technology vol. 2, no. 1, pp. 1-7, 2013.

[14] M. Vishwanath, and E. Sanjay, "A high-speed, low power consumption D Flip Flop for high speed frequency detector and frequency divider," International Journal of Electronics and Communication Engineering and Technology vol. 5, no. 8, pp. 185-193,2014.

[15] F. B. N. Al Amin, N. Ahmad, and M. H. Jabbar, "A low power CMOS phase frequency detector in high frequency PLL system,” Journal of Physics: Conference Series, vol. 1049, no. 1, pp. 1-8, 2017.

[16] S. B. Rashmi, and S. S. Yellampalli, "Design of Phase Frequency Detector and Charge Pump for High Frequency PLL," International Journal of Soft Computing and Engineering, vol. 2, no. 2, pp. 88-92, 2012.

[17] J. W. Park, "Integrated high voltage boost converter with LC filter and charge pump," Microelectronic International, vol. 31, no. 1, pp. 54-60, 2013.

[18] I. Toihria, "Design of an effective charge pump-phase locked loops architecture for RF applications," International Journal of Coumputer Application, vol. 74, no. 3, pp. 38-44, 2016.

[19] K. K. Patel, N. D. Patel, and K. P. Thakore, "Charge pump, loop filter and VCO for phase lock loop using $0.18 \mu \mathrm{m}$ CMOS technology," Journal of VLSI and Signal Processing, vol. 2, no. 4, pp. 21-25, 2013

[20] N. Ahmad, N. A. B. Ishaimi, and M. H. Jabbar, "Charge pump and loop filter for low power PLL using 130nm CMOS technology," Journal of Physics: Conference Series, vol. 1049, no. 1, pp. 1-10, 2017.

[21] M. Ali, M. Sawan, et al, "FM-UWB transmitter for wireless body area networks: Implementation and simulation," 2016 IEEE International Symposium on Circuits and Systems (ISCAS), pp. 2395-2398, 2016.

[22] M. Ali, H. Shawkey, and A. Zekry, "A 750 $\mathrm{W}$ 3.5-4.5GHz FM-UWB transmitter," J. Electr. Syst. Inf. Technol., vol. 2, no. 1, pp. 133-140, 2015.

[23] M. Ali, H. Shawkey, and A. Zekry, "Ultra-low power 3.5-4.5GHz FM-UWB transmitter," 2013 Saudi Int. Electron. Commun. Photonics Conf. SIECPC 2013, pp. 5-8, 2013.

[24] N. Ahmad, M. K. K. B. Ibrahim, and M. H. Jabbar, "Low Power Ultra-Wideband VCRO in 130nm CMOS Technology," Journal of Physics: Conference Series, vol. 1049, no. 1, pp. 1-9, 2017.

[25] R. Ranjan, A. Raman, and N. Kashyap, "Low Power and High Frequency Voltage Controlled Oscillator for PLL Application," 2019 6th International Conference on Signal Processing and Integrated Networks (SPIN), pp. 212214, 2019.

[26] S. Chauhan, et al, "CMOS Design and Performance Analysis of Ring Oscillator for Different Stages," International Journal of Engineering Trends and Technology (IJETT), vol. 32, no. 5, pp. 234-237, 2016.

[27] S. Suman and P. B. P. Singh, "Design of Temperature Sensor Using Ring Oscillator," International Journal of Scientific \& Engineering Research, vol. 3, no. 5, pp. 1-7, 2012

[28] B. S. Patro, J. K. Panigrahi, and S. K. Mandal, "A 6-17 GHz linear wide tuning range and low power ring oscillator in 45nm CMOS process for electronic warfare," 2012 International Conference on Communication, Information \& Computing Technology (ICCICT), pp. 1-4, 2012. 


\section{BIOGRAPHIES OF AUTHORS}
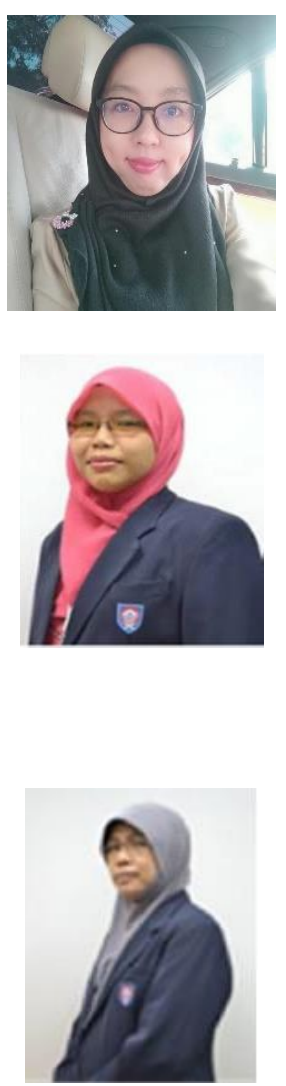

Fadhilah Binti Noor Al Amin received the Bachelor Degree of Electronic Engineering majoring in Microelectronic from Universiti Tun Hussein Onn Malaysia (UTHM), Batu Pahat, Johor, Malaysia in 2017. She is currently a postgraduate student of Master Degree in Electrical Engineering in Universiti Tun Hussein Onn Malaysia (UTHM). Currently she is involving in Integrated Circuit (IC) design project in term of low power and high performance on $90 \mathrm{~nm}$ CMOS technology design. Her major research interest includes VLSI circuit design and IC design using Synopsys EDA tools at schematics and physical design level of a system.

Nornabihah bt Ahmad received her Ph.D in Electronic Engineering from Massey University, New Zealand in 2014. She is a senior lecturer at the Department of Electronic Engineering, Faculty of Electrical and Electronic Engineering, Universiti Tun Hussein Onn Malaysia (UTHM). She received a Bachelor of Electrical, Electronic and Systems with Honours from Universiti Kebangsaan Malaysia and Master of Electronic Engineering (Microelectronic) from Kolej Universiti Tun Hussein Onn Malaysia in 2002 and 2005, respectively. She has published a number of research papers in international journals and conferences in the area of Digital, Analog Integrated Circuir Design and VLSI Design. Her research interests include IC design, low power VLSI circuit design, cryptography co-processor, SoC, low power digital system and ASIC/FPGA design. She is currently a member of Board of Engineers Malaysia (BEM), IEEE, IEEE Young Profesionals and IEEE Circuit and System.

Siti Hawa Ruslan received her Masters in Electrical Engineering from Universiti Teknologi Malaysia in 1991 and Bachelor of Science in Electrical Engineering from University of Miami, Florida, USA in 1987. Her research interests include IC design, low power VLSI circuit design and device modelling and simulation. She has published a number of research papers in international journals and conference proceedings in the area of digital and analog integrated circuit design. She is an associate professor at the Department of Electronic Engineering, Faculty of Electrical and Electronic Engineering, Universiti Tun Hussein Onn Malaysia. She is a senior member of IEEE. 